\title{
Clinical Presentation, Management and Outcome of Japanese Patients With Acute Myocardial Infarction in the Troponin Era
}

\section{- Japanese Registry of Acute Myocardial Infarction Diagnosed by Universal Definition (J-MINUET) -}

Masaharu Ishihara, MD; Masashi Fujino, MD; Hisao Ogawa, MD; Satoshi Yasuda, MD;

Teruo Noguchi, MD; Koichi Nakao, MD; Yukio Ozaki, MD; Kazuo Kimura, MD;

Satoru Suwa, MD; Kazuteru Fujimoto, MD; Yasuharu Nakama, MD; Takashi Morita, MD;

Wataru Shimizu, MD; Yoshihiko Saito, MD; Kennichi Tsujita, MD; Kunihiko Nishimura, MD; Yoshihiro Miyamoto, MD on behalf of the J-MINUET investigators

(Circ J 2015; 79: 1255-1262)

The authors apologize for the incorrect statement in the Methods section. The correct statement is shown below.

Page 1256, right column, lines 10-12:

Incorrect:

Consecutive patients hospitalized within $48 \mathrm{~h}$ of onset of AMI at 28 Japanese medical institutions were enrolled between July 2013 and May 2014.

Correct:

Consecutive patients hospitalized within $48 \mathrm{~h}$ of onset of AMI at 28 Japanese medical institutions were enrolled between July 2012 and March 2014. 